\section{PSQ-003 EFFECTIVENESS OF ANTIEMETIC THERAPY DURING CHEMOTHERAPY IN A REGIONAL HOSPITAL}

${ }^{1} \mathrm{C}$ Salom*, ${ }^{2} \mathrm{MDLE}$ Galceran, ${ }^{1} \mathrm{~J}$ Serrais, ${ }^{1} \mathrm{~A}$ Retamero, 'RM Parés, ${ }^{1} \mathrm{X}$ Sànchez, ${ }^{1} \mathrm{M}$ Medina, ${ }^{3} \mathrm{MA}$ Roch, ${ }^{1} \mathrm{D}$ Ferràndez. ${ }^{1} \mathrm{H}$ osp D'igualada, Pharmacy, Barcelona, Spain: ${ }^{2}$ Hosp D'igualada, Nursing, Barcelona, Spain; ${ }^{3}$ Hospital Joan Xxiii, Pharmacy, Tarragona, Spain

10.1136/ejhpharm-2020-eahpconf.320

Background and importance Chemotherapy induced nausea and vomiting (CINV) remains an important adverse effect as it affects the quality of life of patients, implies chemotherapy dose reductions and compromises adherence.

Aim and objectives To evaluate the effectiveness of antiemetic therapy in the control of CINV, comparing groups of patients with adequate and inadequate patterns, according to clinical practice guidelines.

Material and methods This was a longitudinal retrospective study for population characterisation and non-intervention. Patients receiving intravenous chemotherapeutic treatment from April to July 2018 were included. Independent variables: demographics (age and sex), and adequacy of the guidelines. Dependent variables: chemotherapy induced nausea (CIN), quantified by adding the scores obtained through a self-administered questionnaire based on the CTCAE scale, for the three phases (anticipated+acute +delayed); and chemotherapy induced vomiting (CIV), similarly quantified.

Data are expressed as mean (SD) for continuous variables and absolute and relative frequency for categorical variables. Multivariable logistic regression models were used to study the association of adequacy and effectiveness. Statistical analyses were performed with the $\mathrm{R}$ software (V.3.4.3). A $\mathrm{p}$ value $<0.05$ was considered statistically significant.

Results A total of 797 chemotherapy cycles were administered to 148 patients during the study period. Of these, 133 patients aged $62.26(11.13)$ years, $70(52.63 \%)$ women, were included. They were divided into three groups, according to the adequacy of the guidelines: sufficient (75), excessive (38) and insufficient (20).

The excess deviations $(\mathrm{OR}=0.311(0.038,1.535), \mathrm{p}=0.197)$ or insufficient adequacy $(\mathrm{OR}=0.388(0.057,1.878), \mathrm{p}=0.278)$ were not predictors of nausea. In contrast, insufficient adequacy was a predictor of vomiting $(\mathrm{OR}=17.907$ (2.078, 290.042), $\mathrm{p}=0.015)$, while the excess deviation was not $(\mathrm{OR}=1.799$ (0.064, 37.415), $\mathrm{p}=0.688)$.

Conclusion and relevance For all CINV anticipated, acute and delayed phases considered together, an insufficient antiemetic pattern was associated with worse control of vomiting, but not nausea. In future studies, separate assessment of the influence of the adequacy of the antiemetic pattern on each of the CINV phases deserves further investigation.

\section{REFERENCES AND/OR ACKNOWLEDGEMENTS}

No conflict of interest.

\section{PSQ-004 ADEQUACY OF ANTIEMETIC TREATMENT DURING CHEMOTHERAPY IN A REGIONAL HOSPITAL}

${ }^{1} \mathrm{C}$ Salom*, ${ }^{2}$ MDLE Galceran, ${ }^{1} \mathrm{~J}$ Serrais, ${ }^{1} \mathrm{~A}$ Retamero, ${ }^{1}$ RM Parés, ${ }^{1} X$ Sànchez, ${ }^{1} \mathrm{M}$ Medina, ${ }^{3} \mathrm{MA}$ Roch, 'D Ferràndez. 'Hosp D'igualada, Pharmacy, Barcelona, Spain; ${ }^{2}$ Hosp D'igualada, Nursing, Barcelona, Spain; ${ }^{3}$ Hospital Joan Xxiii, Pharmacy, Tarragona, Spain

10.1136/ejhpharm-2020-eahpconf.321
Background and importance Despite the availability of international guidelines for antiemetic treatment in chemotherapy, their implementation during daily clinical practice is not optimal.

Aim and objectives To assess adaptation of the antiemetic pattern to the degree of chemotherapy emetogenicity in a regional hospital, according to the clinical practice guidelines of MASCC/ESMO, ASCO and NCCN.

Material and methods A longitudinal retrospective study was conducted for population characterisation and non-intervention. Patients receiving intravenous chemotherapeutic treatment from April to July 2018 were included. Demographic variables (age and sex), indication for chemotherapy, scheme, cycle, administration of $5-\mathrm{HT}_{3}$ antagonists, $\mathrm{NK}_{1} \mathrm{R}$ antagonists, dexamethasone, and other antiemetics, and adaptation of the antiemetic treatment to guidelines were collected.

Data are expressed by mean (SD) for continuous variables and by absolute and relative frequency for categorical variables. Statistical analysis was performed with $\mathrm{R}$ software (V.3.4.3).

Results The sample included 133 patients, aged 62.26 (11.13) years and $70(52.63 \%)$ were women. They received chemotherapy for 12 different indications, with 45 different schemes, 66.92\% undergoing their first cycle, and $33.08 \%$ their second or later. No patient was included at different cycles of his/her treatment.

On the day of chemotherapy, 121 (90.98\%) patients received antiemetic monotherapy or polytherapy. A total of $112(84.21 \%)$ patients received a 5- $\mathrm{HT}_{3}$ antagonist, 69 (51.88\%) an $\mathrm{NK}_{1} \mathrm{R}$ antagonist and 112 (84.21\%) dexamethasone. In the following days, $58(43.61 \%)$ patients received monotherapy or polytherapy. Mainly, 34 (25.56\%) were given dexamethasone, $10(7.52 \%)$ a metoclopramide fixed schedule, $5(3.76 \%)$ metoclopramide on demand and $5(3.76 \%)$ a 5 $\mathrm{HT}_{3}$ antagonist.

Adequacy of the recommendations of the guidelines was sufficient in $75(56.39 \%)$ patients, while the remaining presented an excessive pattern (38 (28.57\%) patients) or insufficient pattern (20 (15.04\%) patients). The proportion of sufficient adequacy in the hospital population was estimated at $0.56(0.47-0.64)$.

Conclusion and relevance Only slightly more than half of the patients received an antiemetic pattern in accordance with the internationally agreed clinical guidelines, so there is ample room for improvement. Among those with a non-consistent pattern, an excessive pattern was much more frequent.

\section{REFERENCES AND/OR ACKNOWLEDGEMENTS}

No conflict of interest.

\section{PSQ-005 ANALYSIS OF THE ADEQUACY OF VITAMIN D PRESCRIPTIONS}

${ }^{1}$ IM Carrión Madroñal*, 'N Martín Fernández, ${ }^{2} Y$ Arco Prados, 'S Grutzmancher Saiz, ${ }^{1}$ MD Santos Rubio. ${ }^{1}$ Hospital Universitario Juan Ramón Jiménez, Pharmacy Department, Huelva, Spain; ${ }^{2}$ Distrito Sanitario Huelva-Costa, Primary Care Pharmacy, Huelva, Spain

\subsection{6/ejhpharm-2020-eahpconf.322}

Background and importance In recent years, a considerable increase in vitamin $\mathrm{D}$ determinations and supplementation has been observed, although there is uncertainty about its clinical benefit in situations other than osteomalacia and rickets. In addition, according to the Spanish Agency for Medicines and 